\title{
Single and Sequential Extraction of Cadmium in Some Highly Calcareous Soils of Southwestern Iran
}

\author{
A. Khanmirzaei*1, K. Bazargan ${ }^{2}$, A. Amir Moezzi ${ }^{1}$, B. K. Richards ${ }^{3}$, K. Shahbazi ${ }^{2}$ \\ ${ }^{1}$ Department of Soil Science, Science, college of Agriculture, Shahid Chamran University, Ahwaz, Iran. ${ }^{2}$ Soil and Water Research \\ Institute of Iran, Karaj, 31785-311 Iran ${ }^{3}$ Department of Biological and Environmental Engineering, Riley-Robb Hall, Cornell \\ University, Ithaca, NY 14853-5701, USA. *Corresponding author. email: alikhanmirzai@yahoo.com Tel.: +98-261-3203575
}

\begin{abstract}
:
Thirty-two surface soil samples with different physical and chemical properties were collected from calcareous soils of arid regions of Khuzestan Province, Southwestern Iran. Actual and potential cadmium (Cd) bioavailability was assessed by means of a greenhouse study, two different single extractions: 0.005 DTPA and 0.05 EDTA and two sequential extraction procedures: modified five-step Tessier method and the three-step BCR method. Extraction results were correlated with grain $\mathrm{Cd}$ uptake by Durum wheat (Triticum durum L. ) grown under greenhouse conditions. Cadmium in the durum grain ranged from 0.064 to $0.273 \mathrm{mg} \mathrm{kg}^{-1}$. The results showed better suitability of DTPA extraction in these highly carbonated soils than EDTA extraction for predicting Cd phytoavailability. DTPA - extractable Cd was positively related to soil electrical conductivity $(p<0.01, \mathrm{r}=0.65)$. Cadmium was predominantly associated with carbonate fraction in these soils (Tessier procedure $40 \%$ and BCR $44 \%$ ). $1 \mathrm{M}$ $\mathrm{NH}_{4} \mathrm{OAc}$ which extracted the soluble + exchangeable fraction in the Tessier scheme may also provide useful information on $\mathrm{Cd}$ availability in studied soils.
\end{abstract}

Keyword: contamination, cadmium, sequential fractionation, wheat

\section{Introduction}

The chemical form of the metal determines whether it is bioavailable which are bound or associated with different soil constituents (Shuman, 1991). The degree of metal association with soil constituents depends on soil physical and chemical properties primarily soil $\mathrm{pH}$, soil solution ionic composition, chloride concentration in soil solution, CEC, clay mineral content and types, organic matter content, calcium carbonate equivalent, oxides of $\mathrm{Fe}, \mathrm{Mn}$, and $\mathrm{Al}$, and redox conditions (Naidu et al., 1994). Single and Sequential extraction techniques are widely used to characterize the metal fractions in soils and sediments and predict their mobility and bioavailability (Ahnstrom and Parker, 1999; Tessier, 1979). A single extraction method is designed to dissolve a phase whose elemental content is easily mobilizable and ideally is correlated with the 
plant bioavailability of the element. In sequential extraction techniques, a sample is treated with a series of progressively harsher reagents to dissolve increasingly recalcitrant forms. In the case of heavy metals, these methods operationally estimate the amounts of metals, in various solid pools, which commonly termed exchangeable, carbonate bound, $\mathrm{Fe}-$ Mn oxide bound (Reducible), organic (Oxidisable) and residual. Ideally, the reagents are chosen to selectively attack a specific soil compartment with minimal dissolution of non-targeted phases (Ahnstrom and Parker, 1999). Although these techniques have been in use for four past decades (Gibbs, 1973; Tessier et al., 1979), there are no universally accepted procedures in terms of reagents and their order in the sequence (Sutherland et al., 2000). This variability limits both method validation as well as comparability of results obtained under multiple extraction regimes.

In order to establish a uniform extraction procedure the European Standards, Measurements and Testing Programme (formerly BCR) introduced the standardized sequential extraction procedure (Ure et al., 1993). This procedure has been standardized and applied to a variety of matrices including sediments, soils; sewage sludge, mining wastes etc., and some modifications have been suggested during the evaluation of the scheme (Sahuquillo et al., 1999; Sulkowski et al., 2006). Of particular concern here is the fact that the BCR scheme considered the soluble, exchangeable and carbonates fractions as a single fraction with uniform potential bioavailability. However, in highly calcareous soils the low-solubility carbonate fraction is predominant (Rajaei et al., 2006). This suggests that the BCR scheme may be inadequate for predicting potential $\mathrm{Cd}$ solubility and plant availability. As such, the potentially bioavailable fraction which correlates with plant uptake should be considered and separately distinguished in the sequential extraction schemes.

The soils of Khuzestan province, a primary crop production area in Southwestern Iran, are extremely carbonated, with more than 40 percent carbonate content in most parts. Agricultural activities are extensive in the area and application of inorganic fertilizers, especially phosphorous, has caused elevated $\mathrm{Cd}$ levels in soils and grain crops produced in the area (Jafarnejadi et al., 2011). Nevertheless, there has been very limited information on cadmium $\mathrm{Cd}$ status and, chemical forms, which is needed to evaluate the actual and potential $\mathrm{Cd}$ mobility and bioavailability in the region's soils.

To evaluate the adoption of the BCR scheme modified for carbonate rich soils (Sulkowski et al., 2006) in calcareous soils of the region, we compared the results of this scheme with those of the extraction protocol of Tessier et al. (1979) which is, typically used for analysis of the calcareous soils of Iran (Abbaspour et al., 2007; Jalali and Khanlari, 2008). These were also compared with standard single step extraction protocols (DTPA and EDTA). The objectives of this study, therefore, were (i) to evaluate the Cd phytoavailability by growing a wheat crop in a greenhouse condition, (ii) to the determine the major soil fractions that contain bioavailable $\mathrm{Cd}$ in a wide range of soils of Khuzestan province using two single and two sequential extraction schemes.

\section{Methods and Materials}

\subsection{The Study area and soil sampling}

This investigation was conducted using 32 surface soil $(0-20 \mathrm{~cm})$ samples collected at different randomly selected farms in an area of approximately $4000 \mathrm{~km}^{2}$ , representing different soil types of calcareous soils in arid region of Khuzestan Province, Southwestern Iran, $\left(47^{\circ} 40^{\prime}\right.$ to $50^{\circ} 33^{\prime} \mathrm{N}$ and $29^{\circ} 57^{\prime}$ to $\left.57^{\circ} 33^{\prime} \mathrm{E}\right)$. The climate vary from semiarid to arid with a mean annual precipitation and class A pan evaporation of 240 and $3000 \mathrm{~mm}$, respectively (Farshi et al., 1997). The physiography of the region ranged from piedmont plains to lowlands in the south. The soils are highly calcareous and are mostly classified as Entisols, 
Aridisols and Inceptisols 17. The region's primary crops are wheat (Tritcum aestivum L.), barley (Hordeum vulgare L.), corn (Zea mays L.), canola (Brassica napus L.), rice (Oryza sativa L.), and vegetables.

\subsection{Soil analysis}

Soil samples were air dried, ground, and passed through a 2-mm sieve. Analyses and methods (Table 1) included: particle size distribution (hydrometer method, Gee and Bauder, 1986); Soil Organic Matter (SOM) content (Walkley-Black procedure; Nelson and Sommers, 1996); Cation exchange capacity (CEC) by replacing cations with $\mathrm{NaOAc}$ (Chapman, 1965); Soil $\mathrm{pH}$ (glass electrode in saturated paste); and Electrical conductivity of saturation extracts by a conductivity meter. Calcium carbonate equivalent (CCE) was determined by neutralization with hydrochloric acid (Leoppert and Suarez, 1996), active calcium carbonate (ACCE) by the $\mathrm{NH}_{4}$-oxalate method (Drouineau, 1942), and manganese oxides (Mnox) were determined using the Loeppert and Inskeep method (1996). Total $\mathrm{Cd}$ concentration was determined by aqua regia procedure (ISO 11466), and all measurements of $\mathrm{Cd}$ concentration were performed by graphite furnace atomic absorption spectrometry (GFAAS) (PG 990).

\subsection{Single and Sequential extraction}

Single extractions were performed using DTPA and EDTA. For DTPA extraction $20 \mathrm{~mL}$ of DTPA $0.005 \mathrm{M}$ and $\mathrm{CaCl} 20.01 \mathrm{M}$ and TEA $0.1 \mathrm{M}(\mathrm{pH} 7.3)$ solution (Lindsay and Norvel, 1978) was added to $10 \mathrm{~g}$ soil in a $125 \mathrm{ml}$ Erlenmeyer flask, shaken for $2 \mathrm{~h}$ in a reciprocal shaker, and filtered through a Whatman No. 597 filter paper. Similar procedure was used for EDTA $(0.05 \mathrm{M}$, $\mathrm{pH} 4.65)$, except that the soil weight was $2 \mathrm{~g}$ and the shaking time was $1 \mathrm{~h}$.

The sequential extraction methods of Tessier et al. (1979) as modified by Tsai et al. (2003) and BCR modified for carbonate rich soils (Sulkowski and Hirner, 2006) were used for partitioning $\mathrm{Cd}$ in the sampled soils. The outlines of these procedures are presented in Tables 2 and 3. Cadmium contents of the final residues (following step 5 for Tessier and step 4 for BCR) was determined by digestion with aqua regia. All extractions were carried out on triplicate $1 \mathrm{~g}$ samples, for each soil, which were placed in a $50 \mathrm{~mL}$ centrifuge tubes of known weight.

Following each step, samples were centrifuged at 6000 rpm for $15 \mathrm{~min}$, and the supernatant liquid was filtered through No. 597 Whatman filter paper.

\subsection{Greenhouse experiment}

Polyethylene pots containing $7 \mathrm{~kg}$ homogenized soil, which were passed through a $5-\mathrm{mm}$ sieve, were prepared in triplicate for each soil. Each pot was treated sufficient $\mathrm{N}$ and $\mathrm{P}$ fertilizer before planting as $\mathrm{Co}\left(\mathrm{NH}_{2}\right)_{2}$ and $\mathrm{H}_{3} \mathrm{PO}_{4}$. Four seeds of Durum wheat (Triticum durum L.) were sown in each pot and grown under greenhouse conditions. The pots moisture was kept near field capacity by frequent watering with deionized water. Plants were grown until maturation of the grain, and harvested. Grain were separated from shells, washed thoroughly with deionized water, ovendried at $70^{\circ} \mathrm{C}$ for $72 \mathrm{~h}$, ground and mixed thoroughly. Digestion of grain was carried out using $\mathrm{HNO}^{3}-\mathrm{HClO}^{4}$ $\mathrm{H}_{2} \mathrm{SO}_{4}$ hot block procedure and concentration of $\mathrm{Cd}$ was determined by graphite furnace atomic absorption spectrometry (GFAAS).

\section{Results and discussion}

\subsection{General soil properties}

General soil properties as well as the results obtained from single extraction of DTPA and EDTA are presented in Table 1. The soils covered a large range of soil properties in terms of electrical conductivity, organic carbon, clay, cation exchange capacity and calcium carbonate equivalent. The $\mathrm{pH}$ values of these severely carbonatic soils were alkaline ranged from 7.05 to 8.37 . Calcium carbonate equivalent contents varied from 26.7 to $63.2 \%$. 
Table1. Selected physical and chemical properties of soils $(n=32)$ as well as cadmium concentration in wheat grain for the soils used in the greenhouse experiment

\begin{tabular}{lcccc}
\hline Characteristics & Range & Median & Mean & SD \\
\hline pH (water) & $7.05-8.37$ & 7.51 & 7.51 & 0.3 \\
EC $\left(\mathrm{dSm}^{-1}\right)$ & $0.8-193.1$ & 5.28 & 16.63 & 34.8 \\
OC $(\%)$ & $0.1-1.2$ & 0.55 & 0.58 & 0.3 \\
CEC $\left(\mathrm{Cmol}_{+} \mathrm{kg}^{-1}\right)$ & $5.2-25.6$ & 15.0 & 14.88 & 5.3 \\
Sand $(\%)$ & $8-60$ & 24 & 27.7 & 14.0 \\
Silt $(\%)$ & $24-62$ & 44 & 45.1 & 7.3 \\
Clay $(\%)$ & $12-46$ & 28 & 27.2 & 11.1 \\
CCE $(\%)$ & $26.7-63.2$ & 44.1 & 43.6 & 9.5 \\
ACCE $(\%)$ & $10.9-27.6$ & 22.0 & 21.0 & 3.7 \\
Mn Oxides $\left(\mathrm{mg} \mathrm{kg}^{-1}\right)$ & $37.5-495$ & 207.7 & 221.4 & 102.5 \\
Total \\
Cd $\left(\mathrm{mg} \mathrm{kg}^{-1}\right)$ & $1-3.3$ & 2.2 & 2.1 & 0.65 \\
EDTA & \\
Dd $\left(\mathrm{mg} \mathrm{kg}^{-1}\right)$ & $0.45-1.65$ & 0.9 & 0.95 & 0.4 \\
Grain $_{\mathrm{Cd}}\left(\mathrm{mg} \mathrm{kg}^{-1}\right)$ & $0.04-0.15$ & 0.06 & 0.065 & 0.02 \\
\hline
\end{tabular}

EDTACd : EDTA-extractable Cd; DTPACd: DTPA-extractable Cd; SD: Standard deviation

A wide range of EC was found, with a minimum of $0.8 \mathrm{dS} \mathrm{m}^{-1}$ and a maximum of $193.1 \mathrm{dS} \mathrm{m}^{-1}$. Total $\mathrm{Cd}$ concentrations in the soils varied from 1 to $3.3 \mathrm{mg} \mathrm{kg}^{-1}$ with mean and median of 2.1 and 2.2 , respectively. This is higher than the threshold recommended for calcareous soils (2 mg kg-1; Wang, 1999) indicating Cd contamination of the studied soils mainly due to application of high-Cd phosphorous fertilizers (Jafarnejadi et al., 2011). Total Cd was correlated (Table 4$)$ only with soil organic carbon $\left(r=0.48^{*}\right)$ this may be as a sequence of higher biomass production in areas with higher phosphorous fertilizers application.

\subsection{Single extraction}

Single extractions can be considered as tools indicating potential release of elements from particular soil constituents with which they are associated. EDTAextractable $\mathrm{Cd}$ concentration varied from 0.45 to 1.65 $\mathrm{mg} \mathrm{kg}{ }^{-1}$ with a mean of $0.95 \mathrm{mg} \mathrm{kg}^{-1}$, whereas, DTPA- 
Table 2. Scheme of metals fractionation proposed by Tessier et al. (1979) modified by Tsai et al.(2003)

\begin{tabular}{|c|c|c|c|c|}
\hline Step & Fraction & Extractant & $\mathrm{pH}$ & Procedure \\
\hline 1 & Soluble+Exchageable & $20 \mathrm{ml} 1 \mathrm{M} \mathrm{NH}_{4} \mathrm{OAc}$ & 7 & $0.5 \mathrm{~h}$ shaking at $25^{\circ} \mathrm{C}$ \\
\hline 2 & Associated with carbonates & $20 \mathrm{ml} 1 \mathrm{M} \mathrm{NaOAc}$ & 5 & $5 \mathrm{~h}$ shaking at $25^{\circ} \mathrm{C}$ \\
\hline 3 & Associated with Mn oxides & $20 \mathrm{ml} 0.1 \mathrm{M} \mathrm{NH}_{2} \mathrm{OH} . \mathrm{HCl}$ in $0.1 \mathrm{M} \mathrm{HNO}_{3}$ & & $0.5 \mathrm{~h}$ shaking at $25^{\circ} \mathrm{C}$ \\
\hline 4 & Associated with Fe oxides & $20 \mathrm{ml} 0.04 \mathrm{M} \mathrm{NH}_{2} \mathrm{OH} . \mathrm{HCl}$ in $25 \% \mathrm{w} / \mathrm{v} \mathrm{HOAc}$ & 2 & $6 \mathrm{~h}$ shaking at $96^{\circ} \mathrm{C}$ \\
\hline \multirow[t]{2}{*}{5} & Associated with organic matter & $5 \mathrm{ml} 0.1 \mathrm{M} \mathrm{HNO}_{3} / 10 \mathrm{ml} \mathrm{H} \mathrm{H}_{2} \mathrm{O}_{2} 30 \% \mathrm{~m} / \mathrm{v}$ & - & $5 \mathrm{~h}$ shaking at $85^{\circ} \mathrm{C}$ \\
\hline & & $+15 \mathrm{ml} \mathrm{NH}{ }_{4} \mathrm{OAc} 3.2 \mathrm{M}$ & & 30 min shaking at $25^{\circ} \mathrm{C}$ \\
\hline 6 & Residual & aqua regia & & \\
\hline
\end{tabular}

-extractable $\mathrm{Cd}$ concentration varied from 0.45 to 1.65 $\mathrm{mg} \mathrm{kg}{ }^{-1}$ with a mean of $0.95 \mathrm{mg} \mathrm{kg}^{-1}$, whereas, DTPAextractable $\mathrm{Cd}$ ranged from 0.04 to 0.15 (mean $=0.065$ ) $\mathrm{mg} \mathrm{kg}^{-1}$ (Table 1). EDTA extraction showed a higher potential mobilization of $\mathrm{Cd}$ than DTPA, releasing $45.7 \%$ of total soil $\mathrm{Cd}$, whereas the percentage of total Cd extracted by DTPA was $3.1 \%$. This difference may be attributedable to the carbonate-dissolving nature of $0.05 \operatorname{EDTA}(\mathrm{pH}=4.65)$ which thus releases part of the element fraction bound in carbonates (McGrath and Cegarra, 1992). The other possible factor is that EDTA dissolves iron oxyhydroxides (Borggard, 1988). As the proportion of metals fractions is controlled by the soil properties (Naidu et al., 1994), correlation analysis was made to assess the soil properties controlling $\mathrm{Cd}$ fractionation in these soils. DTPA-extractable $\mathrm{Cd}$ Concentrations were positively correlated with soil electrical conductivity $(\mathrm{r}=0.65, p<0.01)$, it was reported before by Amini et al. (2005).

\subsection{Sequential extraction}

The two sequential extraction protocols tested have a different number of fractions, but their component can be categorized into four roughly comparable equivalent fractions, acid soluble, reducible, oxidable and residual, which are associated with different forms and availability mechanisms. We use this general framework here to compare the results of the two protocols.

\section{Acid soluble fraction:}

This fraction is subdivided into two separate fractions, water-soluble + exchangeable and carbonate bound, in Tessier's scheme, which had mean concentration of 90.4 and $705 \mu \mathrm{g} \mathrm{kg}^{-1}$, respectively (Table 5). As shown in Table 4, the water-soluble + exchangeable fraction was highly correlated with both DTPA-extractable $\mathrm{Cd}$ and soil electrical conductivity. Displacing $\mathrm{Cd}$ from exchange sites and forming complexes between anions, mostly chloride and $\mathrm{Cd}$, may describe this positive correlation in saline soil conditions (Norvell et al., 2000). The carbonate bound fraction, accounted for about 40 percent of total $\mathrm{Cd}$, and was positively correlated with DTPA extractable $\mathrm{Cd}(\mathrm{r}=0.39 ; p<0.05)$, clay content $(\mathrm{r}=0.42 ; p<0.05)$ and active calcium carbonate $(\mathrm{r}=0.44 ; p<0.05)$. Adsorption isotherms 
of $\mathrm{Cd}$ in 20 highly calcareous soils of Southern Iran carried out by Maftoun et al. (2004) showed that CCE was the main factor controlling the adsorption capacity of $\mathrm{Cd}$ in these soils. Although the Cd extracted in the first equivalent fraction of the two sequential schemes was similar, only the water soluble + exchangeable fraction of Tessier, extracted by a neutral salt, provides useful information relevant to the plant-available fraction. Menzies et al. (2007) concluded that neutral salt solutions such as $1 \mathrm{M} \mathrm{NH}_{4} \mathrm{CH}_{3} \mathrm{COO}$ and $0.01 \mathrm{M}$ $\mathrm{CaCl} 2$ tended to provide the best relationship between the soil extractable $\mathrm{Cd}$ and plant tissue accumulation. On the other hand, carbonates act as strong adsorbents for $\mathrm{Cd}$, and carbonate bound fraction may not be released easily in these highly calcareous soils by weak reagents. As noted by McBride (1994), Cd can complex with carbonates via "solid solution" wherein $\mathrm{Cd}$ can substitute for $\mathrm{Ca}$ in the surface layers of $\mathrm{CaCO}_{3}$ minerals. This fraction is only slowly plant-available but would be rapidly released when the carbonates are dissolved. Thus water soluble+exchangeable and carbonate-bound should be considered (and analyzed) as two different fractions. The highest percentage of total $\mathrm{Cd}(43.9 \%)$ was observed in the acid-soluble fraction of the modified BCR scheme $\left(912 \mu \mathrm{g} \mathrm{kg}^{-1}\right)$, which was correlated with EDTA-extractable $\mathrm{Cd}$ $(\mathrm{r}=0.45 ; p<0.01)$, clay content $(\mathrm{r}=0.85 ; p<0.01)$, cation exchange capacity $(\mathrm{r}=0.55 ; p<0.01)$ and active calcium carbonate $(\mathrm{r}=0.43 ; p<0.05)$.

Reducible fraction: This fraction represents the $\mathrm{Cd}$ associated with $\mathrm{Fe}$ and $\mathrm{Mn}$ oxides that would susceptible to mobilization under altered redox conditions. This fraction is subdivided into separate Fe-bound and Mn-bound fractions in Tessier's scheme, with mean values of 399.4 and $219.7 \mu \mathrm{g} \mathrm{kg}^{-1}$ respectively. The total $\mathrm{Cd}$ extracted in the $\mathrm{Fe}$ and $\mathrm{Mn}$ oxides fractions of Tessier's scheme (619.1 $\left.\mu \mathrm{g} \mathrm{kg}^{-1}\right)$, was greater than the $\mathrm{Cd}$ extracted in the BCR Fe-Mn oxide fraction $\left(320 \mu \mathrm{g} \mathrm{kg}^{-1}\right)$. These differences may be attributed to incomplete dissolution during the soluble + exchangeable phase of Tessier's procedure, allowing additional carbonate dissolution to continue during subsequent extraction steps (Gleyzes et al., 2002).
Organic bound fraction: The average $\mathrm{Cd}$ extracted in Tessier scheme was $210 \mu \mathrm{g} \mathrm{kg}^{-1}$ soils whereas the BCR scheme extracted $169 \mu \mathrm{g} \mathrm{kg}^{-1}$. The two methods studied used $\mathrm{H}_{2} \mathrm{O}_{2}$ reagents for extracting the organicbound fraction, but the oxidation time of Tessire's with $\mathrm{H}_{2} \mathrm{O}_{2}$ is longer which might be expected to released more metal than BCR. Nevertheless, this fraction accounted for 9.6 and $10.1 \%$ of total extracted $\mathrm{Cd}$, respectively. The presence of acetic acid also promotes the release of metals specifically sorbed on inorganic and organic substrates (Tessier et al., 1979; Ahnstrom and Parker, 1999). The soil organic matter content was correlated with the metal amounts bound to the organic $(0.38 ; p<0.05)$ and residual $(0.45 ; p<0.05)$ soil phases when using the $\mathrm{BCR}$ procedure.

The relative amounts of $\mathrm{Cd}$ associated with the generally categorized (as mentioned previously) fractions in the BCR and Tessier schemes had similar rankings: Acid soluble $>$ Reducible $>$ Residual $>$ Organic matter. (Figures 1 and 2) The ranking in the Tessier scheme followed the order: carbonate $>$ residual $>\mathrm{Fe}$ oxides $>$ Mn oxides $>$ organic matter $>$ soluble + exchangeable, which is likely due to the high carbonate and low organic matter content of the soil tested. Although the carbonate fraction contributes to the total labile fraction under more acidic conditions (McBride 1994), only the potentially bioavailable portion of carbonate-bound $\mathrm{Cd}$ should be considered in these highly calcareous soils. Hirsch and Banin (1990) reported that formation of the $\mathrm{CdCO}_{3}$ may control the $\mathrm{Cd}$ solubility at high $\mathrm{Cd}$ concentrations in calcareous soils.

\subsection{Grain uptake and soil extraction}

Cadmium concentration in durum wheat grain varied from 0.064 to $0.273 \mathrm{mg} \mathrm{kg}^{-1}$ with a mean and median concentration of 0.133 and $0.132 \mathrm{mg} \mathrm{kg}^{-1}$, respectively (Table 1 ). The maximum permissible limit for $\mathrm{Cd}$ concentration in wheat grain reported by the Commission Regulation of the European Communities (EC, 2006) is $0.2 \mathrm{mg} \mathrm{kg}^{-1}$ wet weight which indicates mean grain $\mathrm{Cd}$ concentration is not exceeded their threshold value. 
Table 3. The BCR (Community Bureau of Reference) optimized sequential extraction procedure for high carbonate soils by (Sulkowski and Hirner, 2006)

\begin{tabular}{|c|c|c|}
\hline Fraction & Extractant & Procedure \\
\hline Soluble+Exchageable+ Carbonate & $40 \mathrm{ml} 0.11 \mathrm{M} \mathrm{CH}_{3} \mathrm{COOH}$ & $16 \mathrm{~h}$ shaking at $25^{\circ} \mathrm{C}$ \\
\hline Soluble + Exchageable + Carbonate & $40 \mathrm{ml} 0.11 \mathrm{M} \mathrm{CH}_{3} \mathrm{COOH}$ & $16 \mathrm{~h}$ shaking at $25^{\circ} \mathrm{C}$ \\
\hline Soluble+Exchageable + Carbonate & $40 \mathrm{ml} 0.11 \mathrm{M} \mathrm{CH}_{3} \mathrm{COOH}$ & $16 \mathrm{~h}$ shaking at $25^{\circ} \mathrm{C}$ \\
\hline Iron and manganese oxyhydroxides & $\begin{array}{l}40 \mathrm{ml} 0.5 \mathrm{M} \mathrm{NH}_{2} \mathrm{OH} . \mathrm{HCl} \\
\mathrm{pH} 1.5 \text { with } \mathrm{HNO}_{3}\end{array}$ & $16 \mathrm{~h}$ shaking at $25^{\circ} \mathrm{C}$ \\
\hline \multirow[t]{2}{*}{ Organic matter + sulfides } & $10 \mathrm{ml} \mathrm{H} \mathrm{O}_{2} 8.8 \mathrm{M}$ & $2 \times 1$ h shaking at $85^{\circ} \mathrm{C}$ \\
\hline & $50 \mathrm{ml} \mathrm{CH} \mathrm{COONH}_{4} 1 \mathrm{M}$ & $16 \mathrm{~h}$ shaking at $25^{\circ} \mathrm{C}$ \\
\hline Residual & aqua regia & \\
\hline
\end{tabular}

Grain Cd was closely and positively associated with EC $(\mathrm{r}=0.60 ; p<0.01)$, DTPA-extractable $\mathrm{Cd}(\mathrm{r}=$ $0.50 ; p<0.01)$ and the Tessier soluble+exchangeable fraction. Previous studies demonstrated that elevated concentrations of chloride thorough the formation of chloro-Cd complexes could be a explain for the increasing concentrations of $\mathrm{Cd}$ in plants, either through faster $\mathrm{Cd}$ diffusion to roots or transported chlorocomplexes across the root membrane (Norvell et al., 2000). The authors also believed that these complexes lead to Cd release from the solid to the solution phase, thereby enhancing solubility and mobility. The results showed that grain $\mathrm{Cd}$ as a phytoavailability index was positively correlated with soil DTPA-extractable
$\mathrm{Cd}(\mathrm{r}=0.52, p<0.01)$, whereas, this correlation was not found in the case of EDTA-extractable $\mathrm{Cd}(\mathrm{r}=$ $-0.12, p>0.05)$. It means that DTPA is more suitable for predicting $\mathrm{Cd}$ phytoavailability than EDTA in these highly calcareous soils. Among the sequential extraction fractions, grain $\mathrm{Cd}$, positively correlated only with the water soluble + exchangeable fraction $(\mathrm{r}$ $=0.43 ; p<0.05)$, which suggests that $1 \mathrm{M} \mathrm{NH}_{4} \mathrm{OAc}(\mathrm{pH}$ $=7$ ) may also be a good index for phytoavailable $\mathrm{Cd}$, as well as DTPA, in the studied soils. 
Table 4. Correlation coefficients (r) for relationships between EDTA and DTPA-extractable, sequential extracted fractions, grain cadmium and selected soil properties $(n=32)$

\begin{tabular}{|c|c|c|c|c|c|c|c|c|c|c|c|c|c|c|}
\hline \multirow{2}{*}{$\begin{array}{l}\text { Soil } \\
\text { Properties }\end{array}$} & \multirow{2}{*}{$\begin{array}{c}\text { EDTA } \\
\text { Cd }\end{array}$} & \multirow{2}{*}{$\begin{array}{c}\text { DTPA } \\
\text { Cd }\end{array}$} & \multirow{2}{*}{$\begin{array}{c}\text { Grain } \\
\text { Cd }\end{array}$} & \multicolumn{6}{|c|}{ Tessier } & \multicolumn{5}{|c|}{ BCR } \\
\hline & & & & $\begin{array}{l}\text { Ex. } \\
\text { Cd }\end{array}$ & $\begin{array}{l}\text { Car. } \\
\text { Cd }\end{array}$ & $\begin{array}{l}\mathrm{MnOx} . \\
\mathrm{Cd}\end{array}$ & $\begin{array}{l}\text { FeOx. } \\
\text { Cd }\end{array}$ & $\begin{array}{l}\text { OM. } \\
\text { Cd }\end{array}$ & $\begin{array}{c}\text { Res. } \\
\text { Cd }\end{array}$ & $\begin{array}{l}\text { Ex+Car } \\
\text { Cd }\end{array}$ & $\begin{array}{l}\mathrm{Mn}+\mathrm{FeOx} \\
\mathrm{Cd}\end{array}$ & $\begin{array}{l}\text { OM. } \\
\text { Cd }\end{array}$ & $\begin{array}{l}\text { Res. } \\
\text { Cd }\end{array}$ & $\begin{array}{l}\text { Total } \\
\text { Cd }\end{array}$ \\
\hline EDTA $_{C d}$ & 1 & 0.03 & -0.12 & -0.23 & 0.33 & 0.26 & -0.08 & -0.09 & -0.03 & $0.45^{* *}$ & 0.06 & 0.19 & -0.23 & -0.03 \\
\hline DTPA $_{C d}$ & 0.03 & 1 & $0.50^{* *}$ & $0.59^{* *}$ & $0.39 *$ & 0.17 & 0.15 & -0.23 & -0.01 & 0.06 & -0.18 & -0.03 & 0.24 & 0.24 \\
\hline Grain Cd & -0.12 & $0.52^{* *}$ & 1 & $0.43^{*}$ & -0.10 & -0.16 & 0.14 & 0.17 & -0.16 & -0.03 & -0.20 & $-0.37^{*}$ & -0.17 & 0.11 \\
\hline $\mathrm{pH}$ & 0.18 & 0.09 & -0.09 & -0.27 & -0.04 & 0.22 & -0.08 & -0.25 & -0.04 & -0.03 & -0.15 & -0.07 & 0.06 & 0.03 \\
\hline EC & -0.13 & $0.65^{* *}$ & $0.60^{* *}$ & $0.36^{*}$ & -0.01 & -0.12 & 0.01 & -0.03 & 0.05 & 0.02 & $-0.39^{*}$ & -0.15 & 0.35 & 0.27 \\
\hline OC & -0.16 & 0.23 & -0.05 & -0.17 & 0.26 & 0.01 & 0.31 & 0.10 & 0.28 & 0.14 & 0.11 & $0.38^{*}$ & $0.45^{*}$ & $0.48^{* *}$ \\
\hline CEC & 0.17 & 0.06 & -0.22 & -0.31 & 0.32 & $0.39 *$ & -0.18 & 0.11 & 0.17 & $0.55^{* *}$ & 0.04 & 0.30 & 0.01 & 0.22 \\
\hline Sand & -0.27 & -0.07 & -0.05 & $0.37^{*}$ & $-0.40^{*}$ & $-0.36^{*}$ & -0.1 & -0.13 & -0.22 & $-0.75^{* *}$ & 0.17 & -0.13 & -0.02 & -0.28 \\
\hline Silt & 0.01 & 0.15 & $0.37^{*}$ & -0.22 & 0.12 & 0.10 & 0.26 & -0.03 & -0.04 & 0.15 & -0.17 & -0.27 & -0.01 & 0.01 \\
\hline Clay & 0.34 & -0.01 & -0.17 & -0.32 & $0.42^{*}$ & $0.39^{*}$ & -0.04 & 0.18 & 0.31 & $0.85^{* *}$ & -0.11 & 0.34 & 0.04 & 0.34 \\
\hline $\mathrm{CCE}$ & -0.10 & 0.12 & 0.22 & 0.10 & 0.25 & -0.15 & $0.69^{* *}$ & -0.34 & 0.07 & -0.13 & -0.11 & -0.08 & 0.30 & 0.20 \\
\hline ACCE & -0.5 & 0.18 & 0.11 & -0.17 & $0.44^{*}$ & 0.25 & $0.40^{*}$ & 0.03 & 0.17 & $0.43^{*}$ & -0.31 & 0.23 & 0.19 & 0.31 \\
\hline Mn Oxides & 0.31 & -0.12 & $-0.51^{* *}$ & -0.29 & 0.09 & 0.32 & $-0.45^{* *}$ & -0.01 & -0.17 & 0.04 & 0.33 & 0.17 & -0.30 & -0.21 \\
\hline
\end{tabular}

Table 5. Concentration of Cd released in each fraction of Tessier and BCR schemes $\left(\mu \mathrm{g} \mathrm{kg}^{-1}\right)$.

\begin{tabular}{|c|c|c|c|c|c|c|}
\hline \multicolumn{3}{|c|}{ Acid soluble } & \multicolumn{2}{|c|}{ Reducible } & \multirow[b]{2}{*}{ Organic } & \multirow[b]{2}{*}{ Residual } \\
\hline & Soluble + & Carbonate & $\mathrm{Mn}$ & $\mathrm{Fe}$ & & \\
\hline & Exchageable & & Oxides & Oxides & matter & \\
\hline Modified & $90.4 \pm 20$ & $705 \pm 83$ & $219.7 \pm 33$ & $399.4 \pm 106$ & $210 \pm 30$ & $400 \pm 120$ \\
\hline \multicolumn{7}{|l|}{ Tessier } \\
\hline Modified & \multicolumn{2}{|c|}{$912 \pm 100$} & \multicolumn{2}{|c|}{$320 \pm 70$} & $168.8 \pm 41$ & $180.5 \pm 158$ \\
\hline BCR & & & & & & \\
\hline
\end{tabular}




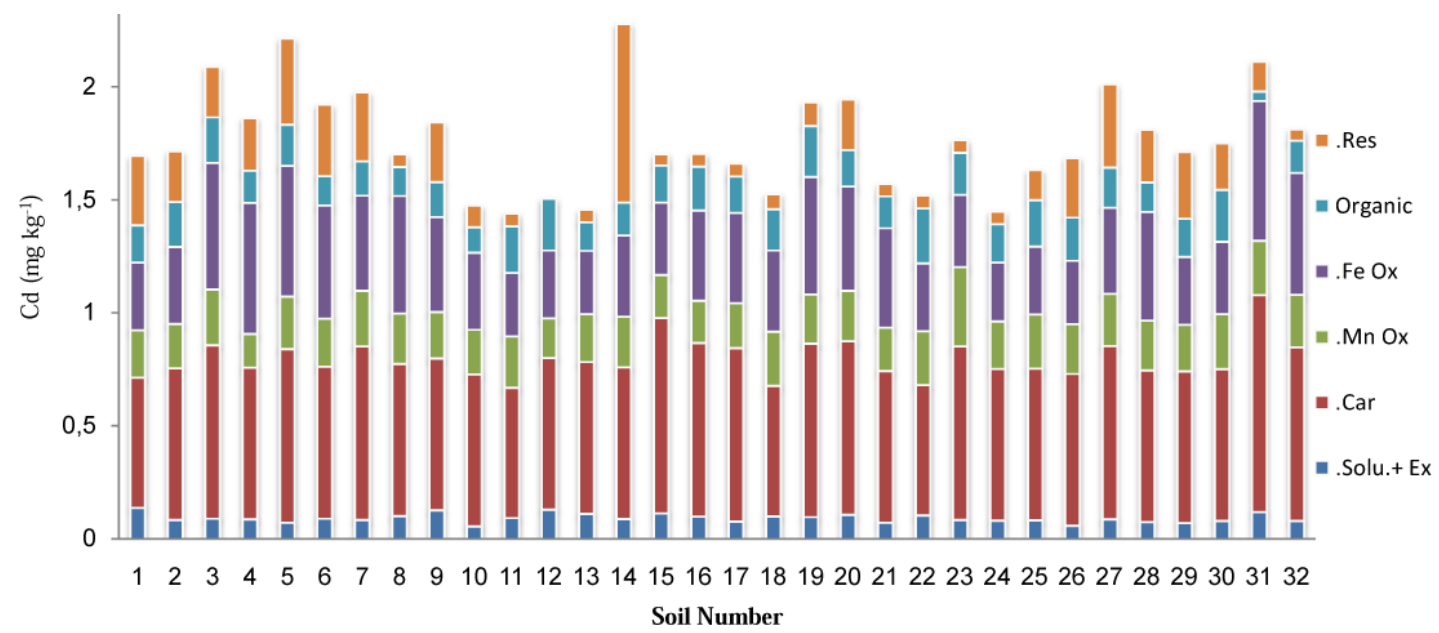

Figure 1. Distribution of solid-phase Cd fractions of the studied soils using the Tessier sequential extraction scheme

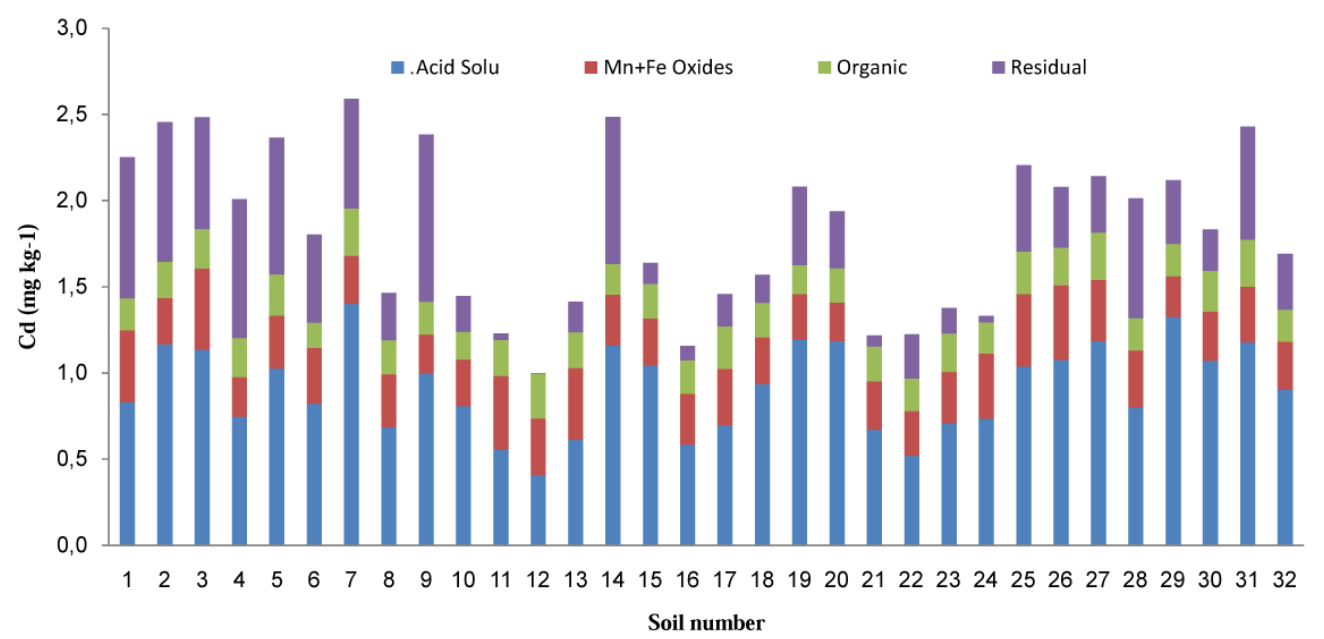

Figure 2. Distribution of solid-phase Cd fractions of the studied soils using the BCR sequential extraction scheme. 


\section{Conclusion}

Among single-step extractions, DTPA correlated better with-phytoavailable $\mathrm{Cd}$ in highly carbonated soils than did EDTA. The $\mathrm{pH} 7 \mathrm{NH}_{4} \mathrm{AOc}$ step of the Tessier protocol (water soluble + exchangeable) also correlated with phytoavailable $\mathrm{Cd}$. While from a theoretical view point, the $\mathrm{Cd}$ released in the acid soluble fraction of the BCR scheme should equal the total of the Tessier soluble + exchangeable and carbonate fractions, the carbonate soils tested showed marked differences between the initial fractions of the Tessier and BCR schemes. Greater amounts of metal released in the acid soluble fraction of the BCR may suggests incomplete dissolution of carbonate phase in the Tessier scheme. Sulkowski and Hirner (2006) showed that $0.11 \mathrm{M}$ acetic acid were not capable of complete dissolution of carbonate fraction in high carbonate soils and, thus proposed repetition of the acetic acid (step 1) extraction until the carbonates are completely destroyed to minimize metal readsorption. Although Tessier and BCR schemes use hydroxylamine hydrochloride for extracting the reducible fraction, differing experimental conditions (reagent concentration and temperature) resulted in the Tessier scheme step having a greater extraction capacity than that of the BCR. Among the sequential extractions tested, the Tessier scheme provided more information about $\mathrm{Cd}$ mobility and bioavailability than the BCR scheme for carbonate rich soils.

\section{Acknowledgement}

This research was supported by the Soil and Water Research Institute of Iran. The authors would like to express their thanks to the analytical assistance provided by Soil chemistry laboratory.

\section{References}

Abbaspour, A., Kalbasi, M., Hajrasuliha, Sh., Golchin, A. 2007. Effects of Plant Residue and Salinity on Fractions of Cadmium and Lead in Three Soils. Soil Sed. Contam. 16, 6, 539 - 555.

Ahnstrom, Z.S., Parker, D.R. 1999. Development and assessment of a sequential extraction procedure for the fractionation of soil cadmium. Soil Sci. Soc. Amer. J. 63, 1650-1658.

Amini, M., Khademi, H., Afyuni, M., Abbaspour, K.C. 2005. Variability of available cadmium in relation to soil properties and land use in an arid region in central Iran. Water Air and Soil pollut. J. 162, $205-$ 218.

Borggard, O.K. 1988. Phase identification by selective dissolution techniquesl. In 'Iron in soils and clay minerals'. (Eds Stucki, J.W., Goodman, B.A., Schwertmann, U.). .pp. 82-98. (Dordrecht, The Netherlands: NATO ASI Series, Reidel.)

Chapman, H.D. 1965. Cation exchange capacity. In: Black, C.A. et al. (eds.). Methods of Soil Analysis: Part 2. Monograph, vol. 9. Agron., SSSA, Madison, Wisconsin. pp. 891-901.

Drouineau, G. 1942. Dosage rapide du calcaire actif du sol: Nouvelles données sur la separation et la nature des fractions calcaires. Annals of Agron. 12, 441-450.

Europian Commission. 2006. Setting maximum levels for certain contaminants in foodstuffs. Commission Regulation (EC) No. 1881/2006 of 19 December 2006. Offical Journal of the Europian Union.

Farshi, A.A., Jaroliahai, R., Ghaemi, M.R., Shahabifar, M., Tavallaei, M.M. 1997. An estimate of water requirement of main field crops and orchards in Iran Agri. Edu. Pub., Tehran, Iran. p.900. 
Gee, G.W., Bauder, J.W. 1986. Particle-size analysis. In: Klute, A. (ed.) Methods of soil analysis: SSSA, Madison, Wisconsin. p. 383-411.

Gibbs, R. J. 1973. Mechanisms of trace metal transport in rivers. Science. 180, 71-73.

Gleyzes, C., Tellier, S., Astruc, M. 2002. Fractionation studies of trace elements in contaminated soils and sediments: a review of sequential extraction procedures. Trends Anal. Chem. 21, 451- 467.

Hirsch, D., Banin, A. 1990. Cadmium speciation in soil solution. J. Environ. Qual. 19, 366-372.

ISO 11466-International Organization for Standardization.1995. Soil quality. Extraction of trace elements soluble in aqua regia ( 6 pp.). Geneva.

Jafarnejadi, A.R., Homaee, M., Sayyad, G., Bybordi, M. 2011. Large scale spatial variability of accumulated cadmium in the wheat farm grains. Soil and Sed. Contam. 20, 98-113.

Jalali, M., Khanlari, Z.V. 2008. Cadmium availability in calcareous soils of agricultural lands in Hamadan, Western Iran. Soil Sed. Contam. 17,3, 256-268

Leoppert, R. H., Suarrez, D.L. 1996. Carbonate and gypsum. In: Sparks, D. L. et al. (eds.). Methods of soil analysis: SSSA, Madison, Wisconsin. pp. 437-474.

Lindsay, W.L., Norvell, W.A. 1978. Development of a DTPA soil test for $\mathrm{Zn}, \mathrm{Fe}, \mathrm{Mn}$, and $\mathrm{Cu}$. Soil Sci. Soc. Amer. J. 42, 421-428.

Loeppert, R.H., Inskeep, W.P. 1996. Iron. In: Sparks, D. L. et al. (eds.). Methods of Soil Analysis: SSSA, Madison, Wisconsin. pp. 639-664.

Maftoun, M., Rassooli, F., Alinejad, Z., Karimian, N, 2004. Cadmium sorption behavior in some highly calcareous soils of Iran, Commun. Soil Sci. Plant Anal. 35, $1271-1282$
McBride, M. B. 1994. 'Environmental Chemistry of Soils'. Oxford University Press, USA

McGrath, S.P., Cegarra, J. 1992. Chemical extractability of heavy metals during and after long-term applications of sewage sludge to soil. J. Soil Sci. 43, 313-321.

Menzies, N.W., Donn, M.J., Kopittke, P.M. 2007. Evaluation of extractants for estimation of the phytoavailable trace metals in soils. Environ. Pollut. 145,1, 121-130.

Naidu, R., Bolan, N.S., Kookana, R.S., Tiller, K.G. 1994. Ionic strength and $\mathrm{pH}$ effects on the sorption of cadmium and the surface charge of soils. Eur. J. Soil Sci. 45, 419-429.

Nelson, D.W., Sommers, L.E. 1996. Total carbon, organic carbon and organic matter. In: Sparks, D. L. et al. (eds.). Methods of soil analysis: SSSA, Madison, Wisconsin. pp. 961-1010,

Norvell, W.A., Wu, J., Hopkins, D.G., Welch, R.M. 2000. Association of Cadmium in Durum Wheat Grain with Soil Chloride and Chelate-Extractable Soil Cadmium. Soil Sci. Soc. Amer. J. 64, 2162-2168.

Rajaei, M., Karimian, N., Maftoun, M., Yasrebi, J., Assad, M.T. 2006. Chemical forms of cadmium in two calcareous soil textural classes as affected by application of cadmium-enriched compost and incubation time. Geoderma. 136, 533-541.

Sahuquillo, A., Lopez-Sanchez, J.F., Rubio, R., Rauret, G., Thomas, R.P., Davidson, C.M. 1999. Use of a certified reference material for extractable trace metals to assess sources of uncertainty in the BCR three-stage sequential extraction procedure. Anal. Chim. Acta 382,3, 317-327.

Shuman, L M. 1991. Chemical forms of micronutrients in soils. In: Mortvedt J.J. et al (eds.). Micronutrients in agriculture: SSSA, Madison, Wisconsin. pp. 113-144. 
Soil Survey Staff. 1999. 'Keys to soil taxonomy'. (Washington, D.C.: U.S. Department of Agriculture, Natural Resources Conservation Service, U.S. Government Printing Office)

Sulkowski, M., Hirner, A.V. 2006. Element fractionation by sequential extraction in a soil with high carbonate content. Appl. Geochem. 21, 1, $16-28$.

Sutherland, R.A., Tack, F.M.G., Tolosa, C.A., Verloo, M.G. 2000. Operationally defined metal fractions in road deposited sediment, Honolulu, Hawaii. J. Environ.Qual. 29, 1431-1439.

Tessier, A., Campbell, P.G.C., Bisson, M. 1979. Sequential extraction procedure for the speciation of particulate trace metals. Anal. Chem. 51, 844851.
Tsai, L.J., Yu, K.C., Chen, S.F., Kung, P.Y., Chang, C.Y., Lin, C.H. 2003. Partitioning variation of heavy metals in contaminated river sediment via bioleaching: effect of sulfur added to total solids ratio. Water Res.37, 4623-4630.

Ure, A.M., Quevauviller, Ph., Muntau, H., Griepink, B. 1993. Speciation of heavy metals in solids and harmonization of extraction techniques undertaken under the auspices of the BCR of the Commission of the European Communities. Inter. J. Environ. Anal. Chem. 51, 135-151.

Wang, H.K. 1999. Heavy metal pollution in soils and its remedial measures and restoration in Mainland China. In: Huang, P.M., Iskander, I.K. (eds.). Soils and Groundwater Pollution and Remediation: Lewis, USA 